\title{
BRINGING THE INTEGRATIVE ASPECT OF SUSTAINABLE DEVELOPMENT INTO COMMUNITY NATURAL RESOURCE MANAGEMENT: THE CASE OF AGRICULTURAL LAND USE IN LIMPOPO, SOUTH AFRICA
}

\author{
C. MUSVOTO, K. NORTJE \& M. MURAMBADORO \\ Council for Scientific and Industrial Research (CSIR), Natural Resources and the Environment, South Africa.
}

\begin{abstract}
Rural communities in South Africa manage natural resources under conditions of resource degradation driven by unsustainable practices. This is against a backdrop of the country adopting the principle of sustainable development and putting in place policies to facilitate integrated decision making, which is pivotal to sustainable development. Sustainable development is an integrative concept with a basis in a 'whole systems approach'. There are no tools tailored to facilitate integration in community level decision making in South Africa and there is need to develop such tools. In line with the stakeholder approach, users have to be involved in the development of the tools and inform their content. The question is whether community level users are able to adequately inform such tools. The objective of this study was to assess the input of potential community level users into development of a decision support tool for improving integration in natural resource management (specifically agricultural land use) decision making. Stakeholder analysis was used to identify decision makers and their responsibilities and elucidate decision-making processes, criteria, context and characteristics of the tool. The main findings were that (i) community agricultural land use decisions focus on addressing social and economic needs with no consideration for the environment; (ii) users visualised the tool as a set of guidelines for enabling equal consideration of social, economic and environmental factors and expected it to facilitate group decision making, communication and participation of different stakeholders in decision making. Stakeholder expectations for the tool were different. Stakeholder analysis was used to accommodate these different perspectives and reach consensus on issues. Stakeholders were able to provide integral information to developing a tool that is both acceptable to users and addresses the integration principle of sustainable development.

Keywords: Agricultural land use, decision-making, integration, natural resources, support, sustainable, tool, utilisation.
\end{abstract}

\section{INTRODUCTION}

In many parts of southern Africa, rural communities are responsible for managing land and other natural resources in their localities [1-5], and this management is effected through various governance models. This is also the case in South Africa, where within rural parts of municipalities, communities are responsible for making decisions on the management and utilisation of natural resources in their areas. Some of these decisions include access to and utilisation of agricultural land. These decisions are made in an environment where unsustainable agricultural practices drive land degradation, in particular destruction of soil composition and structure, soil erosion and siltation of water bodies [6-8]. While community level decision makers grapple with problems related to sustainability of resource use, at national level the country has adopted the concept of sustainable development. In support of its sustainable development trajectory, South Africa has put in place legal instruments and guidelines at both national and local government level. A key legal instrument that underpins sustainable development is the National Environmental Management Act (NEMA) [9]. The Act defines sustainable development as 'the integration of social, economic and environmental factors in the planning, implementation and evaluation of decisions to ensure that development serves both present and future generations'. Furthermore, priority areas of intervention required to achieve sustainable development have been identified, and these include "enhancing systems for 
integrated planning and implementation' and 'sustaining ecosystems and using natural resources sustainably' [10]. The legal instruments and guidelines are meant to facilitate integration and thus sustainability of decisions taken.

The concept of sustainable development was coined in the 1970s and is now widely accepted. However, sustainable development is a fluid concept and has a wide range of meanings, with different entities having their own interpretation of what sustainable development means [11, 12]. Sustainable development is an integrative concept. It calls for a convergence between the three pillars of economic development, social equity and environmental protection [12]. Sustainable development can also be interpreted in terms of consideration of significant environmental, economic and social implications and interactions associated with a policy or issue [13]. Theories of sustainable development stress the need to take a 'whole systems' approach that appreciates emergent properties, complexity and interactions [14]. This paper adopts the definition of sustainable development used in the NEMA Act of South Africa [9] and focuses on the integrative and 'whole systems' aspects of sustainable development, specifically integration of social, economic and environmental factors in community natural resource management decision making. This is in the context of principle 22 of the Rio Declaration on Environment and Development: 'Indigenous people and their communities and other local communities have a vital role in environmental management and development because of their knowledge and traditional practices, and states should support and enable their effective participation in the achievement of sustainable development' [15].

In the South African context, while NEMA provides guidance on integration at national level, the specific integration instrument tailored for the local government level (the lowest level of which is the municipality) is the Integrated Development Plan (IDP). The IDP, a legislative requirement, is a strategic 5-year planning tool, which is standardised across all municipalities. The tool is meant to steer and inform all planning, budgeting, management and decision making in a municipality through consideration of social, economic and environmental factors. Despite sustainable development being the country's chosen development path and the availability of national and municipal level guidelines for integration in decision making and planning, at present there are no guidelines specifically designed for use at community level. Community level guidelines could ensure alignment of resource use decisions with government policies of integration and sustainable development. The IDPs are the only available potential guidelines that could be used to guide decision making towards integration at local level. The IDPs are, however, not designed for community level decision making. An analysis of the IDP and the opinions of community level decision makers[16], showed that a combination of factors, including presentation and focus make the IDP irrelevant for application to local level decision making as an integration tool. It is, however, necessary to support communities in their natural resource management in line with principle 22 of the Rio Declaration on Environment and Development [15].

For sustainable development to be achieved, the principle of integration has to be incorporated into decision making at all levels, including natural resource utilisation decisions at community level. This is not a simple process, as observed by Schwilch et al. [17] who note that in sustainable natural resource management, a balance must be found between the three dimensions of sustainability, namely ecological, economic and socio-cultural, and their objectives and criteria, and this renders decision making highly complex. It has been noted [18] that management for sustainability is inherently more complex than management solely for maximum productivity or conservation, with more facets of the resource base to be monitored and managed and a greater range of potential impacts to be considered. The complexity and uncertainty inherent in managing for sustainability has highlighted the need to change the way in which the environment and resource using activities are 
managed on the basis of robust analysis and evidence. This has resulted in the development of tools to support decision making, and environmental decision support systems, for example, those described by Walker [19] and Guariso and Werthner [20].

In the absence of appropriate tools for use at community level, and the complexity inherent in managing for sustainability, developing tools to guide and support decision making at local level could facilitate the incorporation of integration into local level natural resource management and utilisation decision making. The availability of decision support tools (DSTs) does not, however, necessarily mean that the tools will be used. It has been observed that there has been a long history of irrelevant technology in development contexts of decision support processes and tools as a result of needs being misunderstood, the diversity of goals and conditions being underestimated, and managers' inventiveness being overlooked among other factors [21]. Despite the many decision support systems developed in the field of environmental management, the risk of such systems failing to meet the challenge of real-world problems is reported to be high [22].

\subsection{Involving stakeholders in decision support tool development}

One of the biggest design challenges in developing successful decision support is making it relevant to users' needs and decision-making processes [21]. Development decisions risk being unrealistic or irrelevant if they do not respond directly to stakeholders' problem-specific concerns and related objectives [23]. It has been noted that developing DSTs needs to be compatible with the needs of the users, the capacity of the users, available information, the institutional context in which decisions are made and the technologies and skills available to the developers [19, 21]. It has been argued [22] that there is a widely recognised need to develop new support tools for decision-making in the field of environmental management, with greater attention to the needs of potential users and to identification of the application context.

The involvement of stakeholders, mediated through stakeholder analysis or stakeholder approaches [24-26], is widely acknowledged as critical for success of DSTs [21, 27, 28]. Stakeholder analysis refers to a range of tools or an approach for understanding a system by identifying the key actors or stakeholders [29, 30] on the basis of their attributes, interrelationships and assessing their respective interests related to the system, issue or resource [31]. Although there is a difference in opinion over who or what stakeholders are, this paper adopts Freeman's [24] definition: 'stakeholders are individuals who affect or are affected by certain decisions and actions'. Good practice guidelines for involving stakeholders and/or users in the development of decision and information support tools stress the importance of understanding user needs, being clear about the purpose of the tool, and developers working collaboratively with practitioners and stakeholders $[20,28]$.

Successful engagement with users during the design phase of environmental decision support system development lays the foundation for successful adoption or implementation [28]. It has been found $[32,33]$ that adoption of a decision support system is more likely if it focuses on accomplishing a task that a potential user is already required to do. Involvement of users' needs to be guided by clear objectives and should be aimed at adequately informing the tool under development. Critical up-front questions that need to be addressed as DSTs are being developed include: what the primary purpose of DSTs is; what issues the DSTs will address and who the end-users of the DSTs will be [34]. Using some of these questions to structure the interaction between developers of a tool and the potential users of the tool could improve the quality of information obtained from users.

Natural resource management typically deals with conflicting interests of various stakeholders since they use the same resources for different purposes [35]. It is argued that sustainable 
management of natural resources requires a platform that facilitates learning among stakeholders by sharing, and validating their understanding of the situation in order to reach consensus [36, 37]. Stakeholder analysis can provide such a platform. This analysis can facilitate access to information and perspectives from a wide range of sources, providing a stronger or bigger knowledge base from which to build development or natural resource management initiatives [38, 39]. The inclusive nature of the stakeholder approach could, however, be problematic. Stakeholder analysis, in being used to understand the diverse range of potentially conflicting stakeholder interests [31,40], could exacerbate and generate conflict [41]. In some cases, hidden agendas or covert interests may also skew the analysis [41].

\subsection{The study question and the study area}

In rural areas in South Africa and other parts of the world where communities are responsible for making natural resource utilisation decisions without guidelines to assist them towards integration and sustainable outcomes, the provision of DSTs could improve the way decisions are made. Given the importance attached to involvement of stakeholders or users in developing DSTs, would community level users be able to define such tools and thus ensure their relevance? Using a case study of agricultural land use, this study assessed community input into development of a tool for guiding and supporting integrated natural resource management decision making at community level. The objectives were (i) to understand agricultural land use decision making in the context of integration and (ii) to assess relevance of inputs from community level stakeholders for defining a tool for improving integration in agricultural land use decision making. This study adds to the body of knowledge on the stakeholder approach and its contribution to sustainable resource management and development. The findings of this study could be applied to improving community level stakeholder participation, information gathering and interpretation in DST development.

The study was conducted in Makhado Local Municipality in the Limpopo Province of South Africa. Makhado is a rural municipality in which agriculture is a key livelihood activity and a key component of the landscape. The study site is located on restitution land in wards 17, 19 and 20. In the South African context, a ward is a geopolitical subdivision of a municipality for the purposes of administration and elections. It represents the lowest administrative unit in a municipality. Restitution land is a land category, which came into being after 1994 as a result of the land restitution programme. Land restitution is a South African government programme that restores land rights to persons or communities dispossessed of these rights as a result of past discriminatory legislation and policies, which resulted in forced removals of people from their land. Under the land restitution programme, victims or descendants of those dispossessed of land are given back the land that they were dispossessed of, and this is done within the provisions of the country's constitution. Those who receive land through the restitution process are commonly referred to as 'beneficiaries'. Beneficiaries are responsible for managing restitution land, and they operate through Communal Property Associations (CPAs), within governance arrangements as specified in the country's legislation [42] which enables a community or group (a CPA) to acquire, hold and manage property under a written constitution. CPAs are run by committees made up of elected representatives of a CPA (referred to as CPA executive committees) in terms of the legislation [42].

Integration of social, economic and environmental factors in agricultural land use planning and management is important in Makhado municipality because land under agricultural use has to meet food and different livelihood needs of large numbers of people. Despite their crucial role in livelihoods, agricultural landscapes in Makhado are adversely affected by land degradation, in 
particular destruction of soil composition and structure, soil erosion and siltation of water bodies, with unsustainable agricultural practices being the main driver of these problems $[8,16]$. These environmental problems compromise the capacity of these landscapes to perform the different functions that are expected of them. The lack of integration is a concern, as highlighted in the Makhado Local Municipality IDP [8].

\section{METHODS}

Stakeholder analysis was the key method used in this study, and it involved active participative interaction with stakeholders through semi-structured interviews, stakeholder led categorisation [35], participatory workshops and the anecdote circle [26]. In this paper, the definition of stakeholder put forward by Freeman [24] is used. Stakeholders can be categorised into primary and secondary stakeholders. Primary stakeholders are directly affected (positively or negatively) by proposed interventions/policies/development, whereas secondary stakeholders are those individuals/institutions who are indirectly affected by proposed interventions/policies/development [43]. The benefit of stakeholder analysis is that it allows different stakeholders to identify and voice their interests and be part of the decision-making process in a way that promotes polyvocality and shared trust through interactive sessions where different kinds of knowledge and experiences are valued and shared, thus ensuring greater acceptability of the proposed development/policy/intervention. Including stakeholders, especially primary stakeholders in decision making and policy formulation promotes good governance, democratisation and the transparency of the decision-making processes [44]. However, stakeholder interests and values often diverge from each other and not all interests can be met at the same time and this could generate or exacerbate conflict. Being cognisant of this, in this study stakeholder analysis was used to create room for sharing of all opinions, in other words everyone had a number of opportunities at different times and in different ways to share their opinions and expectations. Realistically not all issues could be dealt with in this study, however, the use of stakeholder analysis gave everyone the opportunity to put their issues on the table, discuss them and then interactively identify the most important and contextually relevant issues.

The primary stakeholders in this study were identified as the CPA executive committees (as representatives of the institution of the CPA), traditional leaders who are part of the beneficiary communities and members of CPAs, whereas secondary stakeholders included the representatives of institutions indirectly involved in or linked to agricultural land use decision making, namely the Makhado Local Municipality, the Department of Agriculture, several government agencies and a Non-Governmental Organisation (NGO), which was working in the area. Participative interaction with the primary and secondary stakeholders was used to gather information on the current agricultural land use decision-making processes and the characteristics and capabilities of a potential tool for integrated agricultural land use decision making. In this study, stakeholder analysis allowed different opinions and perspectives in the stakeholder body to be brought to bear on the development of a DST. This was critical especially for primary stakeholders whose livelihoods depended on the land and would thus be affected by land use decisions. Although there was no conflict in this study, different expectations and perspectives were expressed and researchers facilitated identification of priorities and making final decisions on which the expectations could be met realistically in the context of the research.

Semi-structured interviews were conducted with stakeholders (both primary and secondary) to explore agricultural land use decision making by focusing on the context, criteria for decision making and integration. The interviews were conducted in October 2010. They were followed by two participatory workshops with primary stakeholders in August 2011, one was attended by the local 
leadership (CPA executive committee members) and the other attended by ordinary community members (CPA members) [45]. Two separate workshops were held as the research team was cognisant of how local power relations can affect the participation of some stakeholders in community initiatives as noted in several studies in southern Africa [46-48]. The workshops were designed to give CPA members an opportunity to participate freely and voice opinions without fear of retribution from those in power. The two workshops covered identical issues. The CPAs that participated in this workshop were Shimange, Mavhungeni, Munzhedzi and Manavhela. The purpose of the workshops was for stakeholders to explore and discuss the key features of a potential DST for integrated agricultural land use decision making on restitution land.

The issues covered in the workshops were informed by factors such as relevance of DSTs to users' needs and decision processes [21], responding directly to stakeholders' problem-specific concerns and related objectives [23], identification of the application context of tools [18] and the need to focus on tasks that potential users are already required to do [21, 32, 33]. The concepts of integration and DSTs were explained and discussed with stakeholders at the beginning of the workshops. Each workshop was divided into five information gathering sessions as follows:

\section{a) Identifying decision makers and their responsibilities}

This session was conducted in small groups of less than 10 people. Stakeholders were asked to discuss and list all the people/institutions/forums that make decisions on how land is used for agricultural purposes at community level and to state the responsibilities of the listed people or institutions. The decision makers were then ranked (through discussion and consensus) according to how important they were to decision making (whether decisions on agricultural land use could be made if the particular person/institution was not part of the process). The outputs from the small groups were further discussed in a plenary session and consensus was reached on who the decision makers were, their relative importance and the roles they played.

b) The current situation regarding integration and opportunities and constraints to integration Information on stakeholders' experiences of integration in decision making at the individual household level and at the community level was gathered using the anecdote circle method [26]. The objective was to elicit participants' experiences rather than their opinions in a narrative form. This was done in small groups of not more than 10 people and stakeholders talked about their experiences of decision making and integration. These were recorded and themes were identified from the accounts of different people.

c) Identifying desirable characteristics in a tool for integrated decision making

The characteristics that stakeholders (potential users of the tool) would find desirable in a tool were identified through a discussion guided by the following questions:

'If you lived in an ideal world and you had everything you needed to make integrated agricultural land use decisions which met your needs:

- How would you be making those decisions?

- What structures (institutional arrangements) would be in place to enable you to make those decisions?'

Stakeholders wrote their responses in the form of short phrases on cards. The responses were then displayed, and through discussion similar responses were clustered together and the themes represented by the different clusters identified and recorded. 


\section{d) Capabilities of a tool for integrated agricultural land use decision making}

This session was designed to elicit participants views on what a useful tool should be able to do and how it should be presented to users. A discussion guided by the following questions was held:

'For a planning and decision making tool to be useful to you what should it be able to do for you? How should it be presented?'

A process similar to that used to identify the desired characteristics as described in (c) above was used.

\section{e) Presentation of the tool}

This session sought to get the input of stakeholders on how to present the tool so that it is accessible to them and addresses their needs. A process similar to that used to identify the desired characteristics as described in (c) above was used.

\section{RESULTS AND DISCUSSION}

\subsection{The context of agricultural land use decision making}

Decisions on agricultural land use in restitution areas are made at the community (CPA) level and at the agroecosystem level (representing the household level of decision making). At the community level, decisions relate to the demarcation and allocation of pieces of land for individual household agricultural use. Community level decisions are made by the CPA executive committees in consultation with the CPAs. At the agroecosystem level, decisions relate to the utilisation of land for agricultural production, including clearing of land if required, choice of crops and their management and are made by individual beneficiaries (ordinary CPA members) who have been granted land use rights. Agricultural land use decisions taken by CPA executive committees are influenced by factors such as social relationships (clan relationships) and giving livelihood opportunities to beneficiaries. Clan relationships determine eligibility of individuals for land allocation, and those listed on beneficiary lists (determined by clan relationships) qualify for land allocation.

The decisions taken by individual beneficiaries on what agricultural activities to carry out and how to go about these activities are influenced by the need to generate income, culture, availability of information and markets. Culturally, food crops such as maize and groundnuts have been planted but most of the beneficiaries currently grow vegetables such as cabbage, beetroot and carrots as these have a ready market. Livestock such as poultry and pigs are also reared for sale. Choice of and timing of agricultural operations is in response to projected market demands. Some beneficiaries indicated that they continue to grow crops such as maize, which their parents used to grow as this knowledge has been passed down to them. Availability of knowledge and information also influences individual beneficiaries' choice of activities. Beneficiaries who have worked on commercial farms or attended agricultural training courses have applied this knowledge and this has influenced choice of and management of crops.

Currently, agricultural land use decisions on restitution land are biased towards primarily meeting social and economic needs (Table 1).

Environmental considerations have limited influence on land utilisation decisions. There is little evidence of integration as decisions made by both CPA executive committees and individual CPA members are meant to address specific social and economic needs but do not consider environmental factors. 
Table 1: Classification of factors that influence agricultural land use decision making on restitution land.

\begin{tabular}{lccc}
\hline & \multicolumn{3}{c}{ Classification } \\
\cline { 2 - 4 } Factor influencing decisions & Social & Economic & Environmental \\
\hline Clan relationships & $\checkmark$ & & \\
Providing livelihood opportunities & $\checkmark$ & $\checkmark$ & \\
Culture & $\checkmark$ & $\checkmark$ & \\
Need to generate income & & $\checkmark$ & \\
Need to produce food & $\checkmark$ & $\checkmark$ & \\
External influences, e.g. markets & & & \\
Availability of knowledge and information & $\checkmark$ &
\end{tabular}

3.2 Defining a tool for integrated agricultural land use decision making

A tool for integrated agricultural land use decision making was broadly visualised as a set of guidelines for facilitating the equal consideration of social, economic and environmental factors in decision making. The main features of the tool were described:

\subsubsection{Decision makers and their responsibilities}

The agricultural land use decision makers on restitution land were identified and listed as community members (CPA members or beneficiaries), members of CPA executive committees, some government departments and agencies that work with communities (Table 2). Community members and CPA executive committees (classified as primary stakeholders) had a direct role in decision making while institutions such as the Department of Agriculture (classified as secondary stakeholders) that were listed as decision makers were, on further probing and discussion, found to have no role in decision making. These institutions influenced decision making through provision of information, which informed decisions.

CPA executive committees were ranked the most important decision makers on restitution land, followed by ordinary CPA members, with government departments such as the department of agriculture and the department of rural development in third place. A tool for integrated agricultural land use decision making would thus be targeted at CPA executive committees and CPAs. The identification of decision makers and their responsibilities was conducted as part of the process of defining the scope of the tool and thus its relevance.

\subsubsection{The current situation regarding integration in decision making}

It was noted that consultation was an important component of integration as dialogue within and between communities was necessary for bringing different factors into decision making. The specific experiences relating to integration cited by participants in both workshops were:

- Consultation between communities and among individual households within communities was not routinely done before or during agricultural land use decision making. However, there were instances when there was consultation before land use decisions were made.

- There were also times when neighbouring communities consulted on land use, and the particular example given concerned plans to construct a dam that could potentially flood land belonging to a community downstream of the dam. 


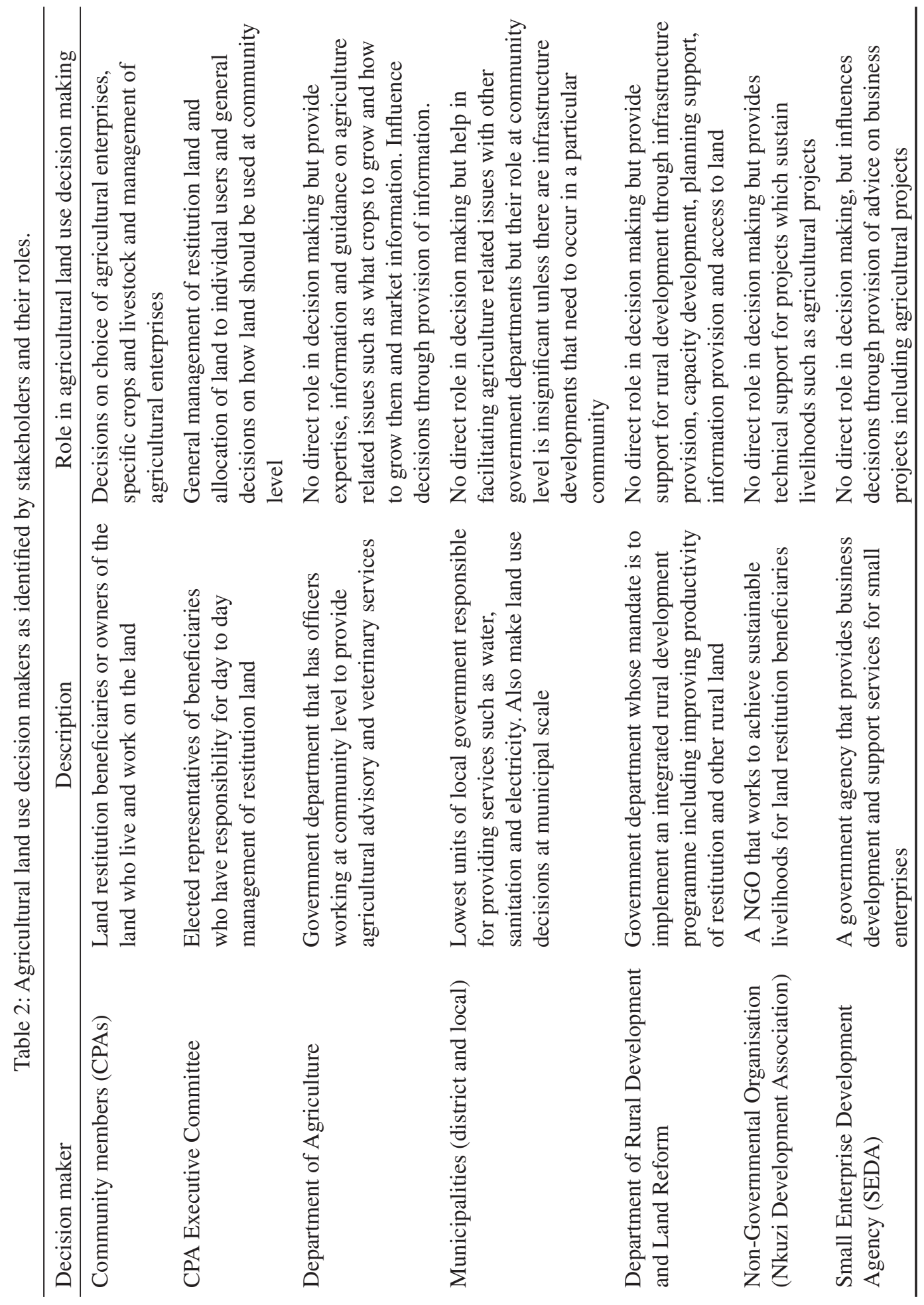


- Community level decisions on land use did not routinely take into consideration what neighbouring communities were doing and the potential impacts of any land use decisions on the environment and on people.

- Within a community, individual households tended to focus on their own agricultural activities and did not concern themselves with what other households in their communities were doing and how activities of different households could impact on each other and on the environment.

- In instances where there was consultation within communities, the consultation was concerned with minimising conflict between different agricultural enterprises and often involved crop and livestock farmers discussing boundaries of grazing and cropping areas and management of livestock to prevent them straying into crop lands.

Participants expressed a lack of trust within communities as a constraint to integration. This lack of trust is characterised by the fact that people do not feel that they can share information or concerns with one another. Similarly, apathy with respect to the implementation of agreed-upon decisions also constrained integration. It was noted that, at community level, if agreements were reached about what to do, there was no follow through and nothing got done. Lastly, lack of what are perceived to be successful agricultural enterprises, which would inspire sharing of experiences, were also cited as a reason for limited consultation.

Opportunities for integration were identified in the fact that although rare, consultation on agricultural land use did take place both within and between communities. The consultation platforms and methods that had been used previously could be used to facilitate consultation for integration. The existence of CPA executive committees, which in principle have to consult community members before making decisions, was identified as an opportunity for integration. The CPA executive committees could play a leading role in facilitating integration in agricultural land use decision making.

\subsubsection{Identifying desirable attributes in a tool for integrated decision making}

Responses to the question on how respondents would be making decisions in an ideal world where everything that was needed for making integrated decisions was available were used to define desirable attributes in a tool. The responses of community leaders and community members are shown in Fig. 1, adapted from [45]. Community leaders' responses were centred on achieving change at community level but did not focus on how this would happen, while community members' responses were concerned with the processes that would be followed to arrive at decisions in an ideal situation and what would need to be in place to support the decision processes.

Some responses of both groups were not directed to the question of how decisions would be made, but reflected general aspirations of the community in terms of creating employment opportunities and attaining food security.

Responses of community members to the question 'If you lived in an ideal world and you had everything you need to make integrated agricultural land use decisions that meet your needs, what structures (institutional arrangements) would be in place for decision making?' mainly focused on the different institutions that should participate in and inform decision making. These responses highlighted the necessity of consultation and coordination in making integrated decisions on restitution land. Community leaders' responses were wide ranging and included factors such as availability of resources (Table 3).

Though the purpose of the exercise and the questions were clearly explained, there were still some responses (Fig. 1 and Table 3) that were not directly relevant to the questions posed and to the broad context of agricultural land use decision making. These responses do, however, highlight general community desires, for example, livelihood opportunities such as jobs. Responses such as "consulting other farmers to share experiences' before making decisions were more directly relevant to the tool 


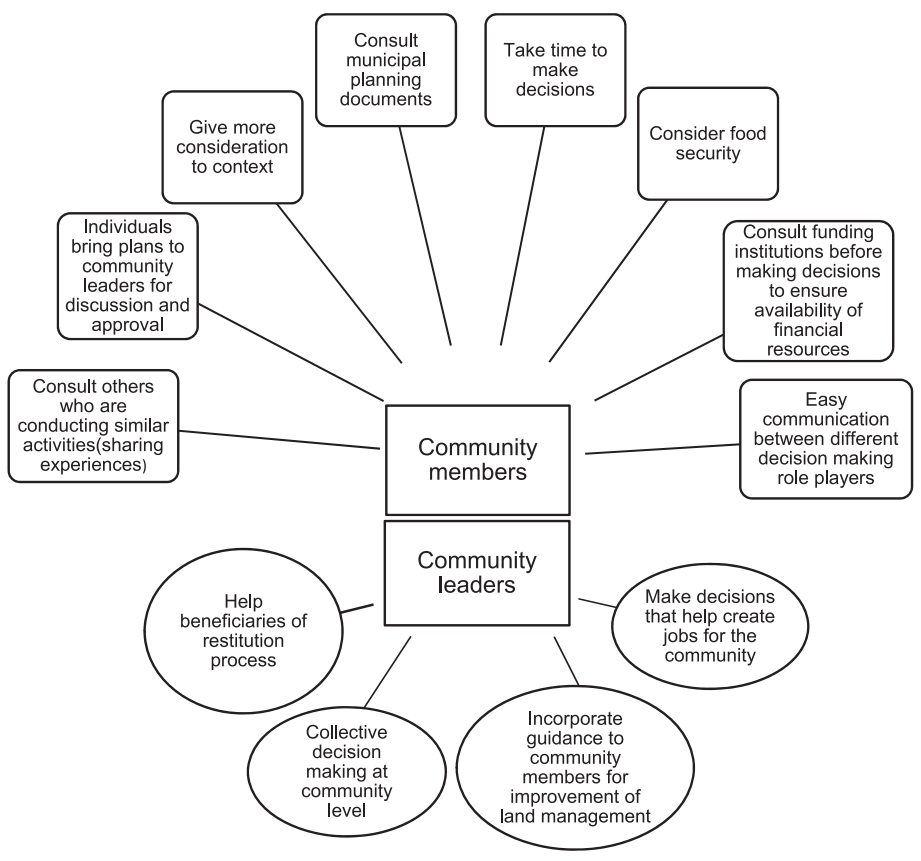

Figure 1: Respondents' perceptions of how agricultural land use decisions would be made in an ideal situation.

Table 3: Perceptions of respondents on structures (institutional arrangements) that would facilitate integrated agricultural land use decision making.

Community leaders

Community members

- Structures that secure markets for people to sell their products

- Quality agricultural products should be accessible and affordable

- Support structures for other stakeholders who have an interest in agriculture and rural development, e.g. agricultural experts providing training to build farming skills

- Structures to enable support from community members, chiefs, CPA executives, municipality and department of agriculture for beneficiaries who need it

- Availability of money

- Structures to facilitate communication between different stakeholders

- Supportive local municipality structures including department of social welfare

- Cooperatives

- Strong CPA structures
- Functional Communal Property Associations

- Involvement of the municipality

- Participation of the Department of Agriculture

- Participation of tribal authorities

- Arrangements that facilitate easy consultation

- Availability of money so that decisions are not hampered by lack of money or infrastructure 


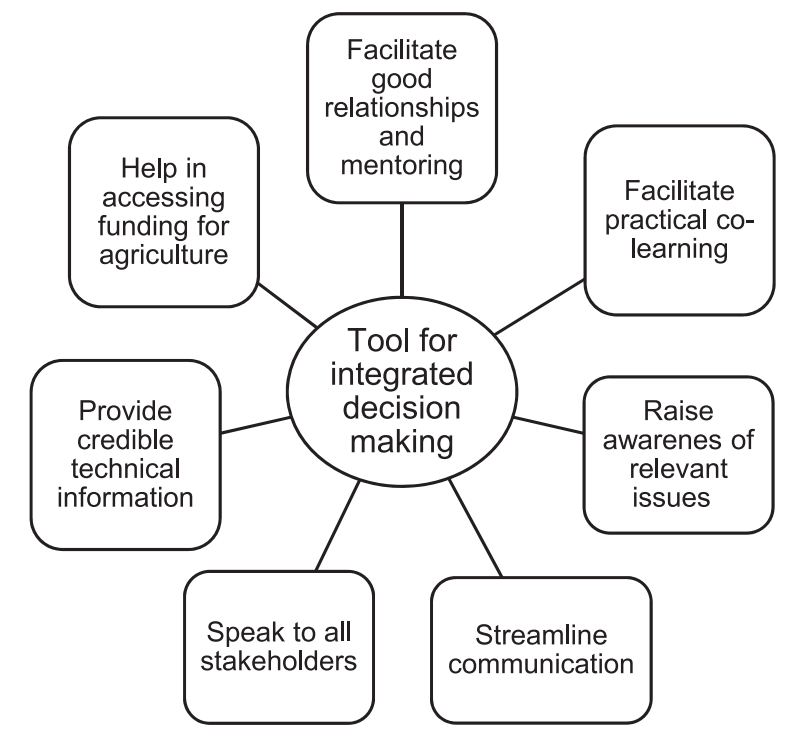

Figure 2: Expected capabilities of a tool for integrated agricultural land use decision making.

and provided insights into what users would find desirable in a tool for integrated agricultural land use decision making.

\subsubsection{Expected capabilities of a tool for integrated decision making}

The discussion on the capability of a tool for integrated decision making was guided by the question: 'For a planning and decision making tool or mechanism to be useful to you what should it do for you?' A useful tool was deemed to have capabilities ranging from streamlining communication to providing credible technical information on agriculture and natural resource management as illustrated in Fig. 2 (adapted from [45]).

Stakeholder expectations were that a tool for integrated decision making should streamline communication between different stakeholders, especially between the CPAs and the various government institutions and provide guidelines to facilitate access to government departments by CPAs. The tool was also expected to speak to all stakeholders, and most importantly to the CPAs and CPA Executive Committees and make sense to and be usable by all stakeholders involved in some way in agricultural land use decision making, from farmer to government official.

Funding and the lack thereof was mentioned as the key factor hampering agricultural production. As such, the participants suggested that a tool for integrated decision making could be helpful if it helped in accessing finding for agriculture through providing information on sources of funding and how to raise funds. Community cohesion was deemed to be central to integrated decision making, and a tool for integrated decision making was expected to facilitate creation of good relations between beneficiaries and mentorship at community level. Related to community cohesion were expectations that the tool should facilitate practical co-learning within communities. Information was central to agricultural activities, and to be relevant to the users, the tool had to be able to provide credible technical information, both in terms of agriculture and natural resource management and in the actual use of the tool. Furthermore, the tool had to raise general awareness of relevant issues such as integrated land use planning and environmental degradation and help communities utilise their land more productively. 
In the discussion that preceded the identification of capabilities of the tool, it was noted that it would be impossible for one tool to have numerous capabilities and it would be necessary to prioritise the capabilities. The priority capabilities were identified as mentorship and giving information, followed by speaking to and giving assistance to CPAs and facilitating access to government departments.

\subsubsection{Presentation of the tool}

Participants were inclined towards a tool that was visual and could be demonstrated. The tool would also have to be presented in a local language and should not only be presented in the written format as that would make it inaccessible to illiterate users (Table 4) [45].

Both community leaders and community members wanted a tool that had practical demonstrable aspects. Community members were concerned with the practical aspects of the tool, for example, language used, whereas community leaders dwelt on the structural aspects of making the tool accessible and its potential implementation, for example, suggestions to structure the tool in the form of workshops and visual media. In developing the tool, the input provided by users would have to be weighed in the context of cost, the social conditions and how conducive they were for accessing some of the media that could be used to deliver the tool and the ease with which users could access and operate some of these media.

Table 4: Perceptions of how a tool for integrated agricultural land use decision making should be presented to make it accessible to potential users.

Community leaders Community members

- Practical - the tool should be in a form that can be demonstrated to users

- Booklet reinforced by other ways of communication: participants commented that while a booklet is a good idea, it is not ideal on its own and should be supported by other ways of transferring the message

- Local media - the tool could be communicated through local media such as community radio stations as this is what people listen to

- Visual - participants mentioned that it might be useful to have a video that explains how the tool works

- Workshops - the tool should be structured around workshops as many participants viewed workshops as an ideal way for the tool to be demonstrated

- Link to existing forums - participants indicated that since there are already established forums it might be a good idea for the tool to be linked to one of the existing forums and to be used through the forum
- Accessible to the illiterate: the tool should be fashioned in such a way that the illiterate can also use it

- Explanations through visuals - the tool should incorporate visual illustrations as participants noted that when something is explained through visual depiction it is easier to understand

- Regular interactions - the tool should facilitate regular interaction between beneficiaries

- Interactive - the tool should be something people can interact with

- Language - the tool should be presented in both English and the local languages 
3.3 Significance of information provided by stakeholders in the development of a tool for integrated agricultural land use decision making

Relevant inputs provided by community leaders and community members (representing different interest groups and thus perspectives) were not identical. The main difference lay in the fact that community leaders emphasised the structural aspects of the tool, whereas community members were concerned with the operational aspects. Both structural and operational aspects should be considered as they impact on the capability of a tool. Stakeholder analysis emphasises accommodation and consensus seeking [49], and in natural resources management stakeholder analysis acknowledges that power relations and disagreeing interests must be considered [50]. According to Billgren and Holmen [51], it is important to observe how various stakeholders relate to each other and to communicate differences between stakeholders in order to create an understanding (even if not an acceptance) of different viewpoints. In this study different perspectives were presented, but not in a conflict situation. Acceptance and accommodation were used to deal with different perspectives. The different perspectives were discussed so that they were understood by all, acknowledged and recorded and were put up for consideration in tool development which followed the workshops.

\subsubsection{Identifying decision makers and their responsibilities}

The exercise of identifying the people and/or institutions who make or influence decisions, the roles they play and their relative importance in decision making, helped to define the users of the tool, and therefore who it should primarily be targeted at and, therefore, the scope of the tool. The decisionmaking roles of the potential users clarified the context in which the tool would be used. This information is also of relevance in ensuring that a tool addresses the needs of decision makers. Addressing decision makers' needs is a key factor in the adoption of a tool, as alluded to by some studies [32, 33], which found that adoption of an environmental decision support system is more likely if it focuses on accomplishing a task that a potential user is already required to do. In this study, stakeholder analysis was useful for clarifying stakeholder roles and thus identifying primary and secondary stakeholders. These distinctions were critical for accurate targeting of the tool as primary stakeholders would be the key users of the tool. The secondary stakeholders, although not playing a role in decision making, have an understanding of agricultural land use on restitution land and would provide relevant input into the development of a DST. Stakeholder analysis has been found to be useful for separating non-stakeholders from real stakeholders [51] and can be used to understand environmental systems by defining the aspects of the system under study; identifying who has a stake in those aspects of the system $[25,31]$.

3.3.2 The current situation regarding integration and opportunities and constraints to integration The experiences of stakeholders who participated in the workshops highlighted the prevailing situation on restitution land as being generally characterised by agricultural land use decision making at both individual household and community level, which is inward looking and does not consider the broad environment in which the community or household is situated. Describing the current situation and identifying potential opportunities and constraints for integration identified the integration issues that the tool would have to address directly or indirectly. The issues include integration of different and potentially conflicting land uses within and between communities and consideration of potential environmental, social and economic impacts of any decisions taken. Consultation between and within communities emerged as a key factor in integrated decision making as it was necessary for different individuals and institutions to exchange information that was pertinent for decision making and to participate in the actual decision making. The necessity for consultation of different institutions and individuals highlighted the importance of coordination in decision making as the different role players would have to participate in decision making in an organised manner if integra- 
tion is to be achieved. Analysis of the current situation also identified opportunities the tool could build on. These opportunities include the fact that consultation between and within communities on agricultural land use takes place intermittently. The tool could use these consultation channels to facilitate routine consultation processes when natural resource decisions are made. The session was also useful as it clarified the fact that the tool would not be able to address all the existing problems, but in so-doing highlighting the areas where it could actually make a difference.

\subsubsection{Identifying desirable characteristics in a tool for integrated decision making}

The exercise of identifying desirable characteristics in a tool was carried out in the context of ensuring relevance of the tool and its adoption. If a tool incorporates characteristics that are deemed desirable by potential users, the tool has a chance of being adopted and used. In identifying desirable characteristics in a tool, it was acknowledged that it would neither be possible nor practical for a tool to incorporate all the attributes identified. Although a tool might only incorporate some of the attributes deemed desirable, its relevance would still be assured because the identified characteristics would have been informed by the experiences and perceptions of potential users of the tool. Some of the participants' responses were directly relevant to the development of a tool for agricultural land use decision making, while other factors reflected participants' concerns and their aspirations in terms of what they want to see happening on restitution land.

\subsubsection{Capabilities of the tool}

The workshops allowed the key potential users of the tool to visualise what a tool that would be useful to them should be able to do. This process was part of understanding what users expect of a tool, and this would be reflective of their needs. Such information also provides clarity on the purpose of the tool. Compatibility with user needs and clarity about the purpose of DSTs have been cited as important factors in the success of these tools [21,28]. In this study, the visualisation of a useful tool was influenced by the realities faced by informants, and some of the realities that were brought in were not relevant to a tool for integrated agricultural land use decision making but to the general issues in the community. However, most of the expected capabilities were relevant to the tool and could be incorporated into tool development. Information on the capabilities of the tool was analysed in the context of what is realistic and possible within the constraints and nuances of the local circumstances as it would not be possible to develop a tool that would have all the listed capabilities.

\subsubsection{Presentation of the tool}

Getting inputs of potential users on how the tool should be presented was meant to ensure that the tool would be structured in a way that made it accessible to the intended users and be compatible with their capacity. It has been noted that DSTs need to be compatible with the capacity of users [21]. Ease of use, or accessibility, has been found to be a key determinant of whether DSTs will be accepted [52]. It has also been pointed out that decision support processes and tools may be physically inaccessible (due to their physical location), technically inaccessible (require technical resources or skills that are not available) or conceptually inaccessible (due to being too difficult) [18]. Engaging with users on how the tool should be presented was meant to address technical and conceptual issues that could render the tool inaccessible to the intended users.

\section{CONCLUSION}

Earlier in this paper it was noted that in order for sustainable development to be achieved, the principle of integration has to be incorporated into decision making at all levels, including natural resource utilisation decisions at community level. It was also noted that integration as an integral part of sustainable development requires a holistic perspective, which appreciates the nuances of 
emergent properties, complexity and interactions of different factors within a system [14]. It was additionally established that NEMA's [9] vision of sustainable development requires a "whole systems' approach, which actively seeks the integration of the social, economic and environmental aspects in order to make relevant and executable decisions [12, 13]. In an effort to address this 'integration-goal' inherent in sustainable development, this study explored the contribution of primary stakeholders to the development of a natural resource management DST for use at community level. By getting community stakeholders to participate more actively in the decision-making process in a way that is informed by both scientific and local knowledge, the decisions around land-use and, therefore, also the management of natural resources can become more sustainable. This paper specifically looked at the efforts to bring together the local knowledge and experiences of stakeholders and scientific knowledge and praxis in order to develop a tool that incorporates the integrative aspect of sustainable development into community level natural resource management.

The stakeholder analysis applied in this study allowed for polyvocal interactions where stakeholders could freely, at different times and in different ways communicate their interests, concerns and ideas. These interactions have revealed important information, which will be integral to developing a tool that is both not only acceptable to the user (the community) but also in line with the goals and principles of sustainable development. Two types of information were obtained from the interactions. First, information regarding the tangible look and feel of the tool, for example, the attributes of the tool, what form it should ideally take and what it should be able to do. This information as sourced from within the community which has to use it, provides the community with an opportunity to own the tool and get a better understanding of how it works. Secondly, the stakeholder interactions revealed the context within which the tool would have to operate. For example, the interactions provided a good understanding of who has a direct role in making land-use decisions; determining constraints to integration within decision-making; identifying opportunities for integration; and generally mapping the contextual environment within which the tool has to exist and operate. This information is crucial for ensuring relevance of the tool and uptake of the 'integration' message of the tool.

While stakeholder analysis generated a wealth of valuable information, it was clear that a single tool would not be able to incorporate all the identified features nor speak to all the contextual nuances. Researchers or facilitators of tool development, therefore, need to make an informed judgement in terms of which information to use and what the capabilities of a potential tool should be as it is not possible to develop a tool, which can do everything. It is clear, however, from this research that stakeholders can contribute to this by prioritising the features and are as such indispensable not only to the process but also to the promotion and uptake of sustainable development principles and goals into community level natural resource management.

\section{REFERENCES}

[1] Zulu, L.C., Community forest management in Southern Malawi: solution or part of the problem? Society and Natural Resources, 21, pp. 687-703, 2008.

[2] Taylor, R., Community based natural resource management in Zimbabwe: the experience of CAMPFIRE. Biodiversity and Conservation, 18, pp. 2563-2583, 2009. doi: http://dx.doi. org/10.1007/s10531-009-9612-8

[3] Bennett, J., Ainslie, A. \& Davis, J. Fenced in: common property struggles in the management of communal rangelands in central Eastern Cape Province, South Africa. Land Use Policy, 27, pp. 340-350, 2010. doi: http://dx.doi.org/10.1016/j.landusepol.2009.04.006

[4] Kanapaux, W. \& Child, B., Livelihood activities in a Namibian wildlife conservancy: a case study of variation within a CBNRM programme. Orynx, 45, pp. 365-372, 2011.

[5] Mbaiwa, J.E., Stronza, A. \& Kreuter, U., From collaboration to conservation: insights from the Okavango delta, Botswana. Society \& Natural Resources: An International Journal, 24, pp. 400-411, 2011. doi: http://dx.doi.org/10.1080/08941921003716745 
[6] Limpopo overview state of the environment, 2003. Available at http://www.environment.gov. za/soer/reports/limpopo/Limpopo.pdf (accessed 12 March 2012).

[7] Limpopo Department of Finance and Economic Development, Limpopo State of the Environment Report (Phase 1), 2004. Available at http://soer.deat.gov.za/dm_documents/Limpopo_ State_of_environment_reporting_phase_1__UrZKg.pdf (accessed 12 March 2012).

[8] Makhado Local Municipality, Integrated Development Plan 2010/11 IDP Review, pp. 43-44, 2010.

[9] Republic of South Africa, The National Environmental Management Act (Act No 107 of 1998). Government Printer, Pretoria, 1998.

[10] DEAT (Department of Environmental Affairs and Tourism), People-planet-prosperity: A National Framework for Sustainable Development in South Africa, 2008.

[11] Giddings, B., Hopwood, B. \& O'Brien, G., Environment, economy and society: fitting them together into sustainable development. Sustainable Development, 10,pp. 187-196, 2002. doi: http://dx.doi.org/10.1002/sd.199

[12] Drexhage, J. \& Murphy, D., Sustainable development: from Brundtland to Rio 2012 background paper prepared for consideration by the high level panel on global sustainability at its first meeting, 2010. Available at http://www.un.org/wcm/webdav/site/climatechange/shared/ gsp/docs/GSP1-6_Background\%20on\%20Sustainable\%20Devt.pdf (accessed 3 October 2012).

[13] United Nations Environment Programme (UNEP), Integrated Policymaking for Sustainable Development. A reference manual. 2009. Available at http://www.unep.ch/etb/publications/ IPSD\%20manual/UNEP\%20IPSD\%20final.pdf (accessed 14 October 2012).

[14] Hardi, P. \&Zdan, T., Assessing Sustainable Development: Principles in Practice. International Institute for Sustainable Development, pp. 12-13, 1997. Available at http://www.iisd.org/pdf/ bellagio.pdf (accessed 9 October 2012).

[15] United Nations Department of Economic and Social Affairs (UN DESA). Report of the United Nations Conference on Environment and Development, Rio de Janeiro, 3-14 June 1992. Annex I. Rio Declaration on Environment and Development, 1992. Available at http://www. un.org/documents/ga/conf151/aconf15126-1annex1.htm (accessed 29 March 2012).

[16] Musvoto, C. Nortje, K., Murambadoro, M. \& Dube, S., Relevance of national and local government policy to sustainable community natural resource management in South Africa. The Sustainable City VII, eds. M. Pacetti, G. Passerini, C.A. Brebbia, \& G. Latini, WIT Press: Southampton and Boston, 1, pp. 317-328, 2012.

[17] Schwilch, G., Bachmann, F. \& de Graaff, J., Decision support for selecting SLM technologies with stakeholders. Applied Geography, 34, pp. 86-98, 2012. doi: http://dx.doi.org/10.1016/j. apgeog.2011.11.002

[18] Walker, D.H. \& Zhu, X., Decision support for rural resource management. Deepening the Basis of Rural Resource Management: Proceedings of a Workshop, eds. I. Guijt, J.A. Berdegué, \& M. Loevinsohn, International Service for National Agricultural Research and red Internacional de Metodología de Investigación de Sistemas de Producción: The Netherlands, pp. 23-35, 2000.

[19] Walker, D.H., Decision support, learning and rural resource management. Agricultural Systems, 73, pp. 113-127, 2002. doi: http://dx.doi.org/10.1016/S0308-521X(01)00103-2

[20] Guariso, G. \& Werthner, H., Environmental Decision Support Systems. Ellis Horwood-Wiley: New York, 1989.

[21] Rizzoli, A.E. \& Young, W.J., Delivering environmental decision support systems: software tools and techniques. Environmental Modelling and Software, 12, pp. 237-239, 1997. doi: http://dx.doi.org/10.1016/S1364-8152(97)00016-9

[22] Giupponi, C., Decision support systems for implementing the European water framework directive: the MULINO approach. Environmental Modelling and Software, 22, pp. 248-258, 2007. doi: http://dx.doi.org/10.1016/j.envsoft.2005.07.024 
[23] Kellon, D. \& Arvai, J., Five propositions for improving decision making about the environment in developing communities: insights from the decision sciences. Journal of Environmental Management, 92, pp. 363-371, 2011.doi: http://dx.doi.org/10.1016/j.jenvman.2010.10.010

[24] Freeman, R.E., Strategic management: a stakeholder approach. Pitman: Boston, 1984.

[25] Grimble, R. \& Wellard, K., Stakeholder methodologies in natural resource management: a review of principles, contexts, experiences and opportunities, Agricultural Systems, 55, pp. 173-193, 1997. doi: http://dx.doi.org/10.1016/S0308-521X(97)00006-1

[26] Callahan, S., How to use stories to size up a situation. Anecdote, Pty. Ltd., 2004. Available at http:// dfaq.uct.ac.za/ngambi/Papers-reworking/Narrative_to_size_up_situation\%20-\%20SCallahan .pdf (accessed 28 March 2012).

[27] Pound, B., Snapp, S., McDougall, C. \& Braun, A. (eds.), Managing Natural Resources for Sustainable Livelihoods: Uniting Science and Participation, Earthscan/IDRC: London, pp. 1-15, 2003.

[28] McIntosh, B.S., Ascough II, J.C., Twery, M., Chew, J., Elmahdi, A., Haase, D., Harou, J.J., Hepting, D., Cuddy, S., Jakeman, A.J., Chen, S., Kassahun, A., Lautenbach, S., Matthews, K., Quinn, N.W.T., Merritt, W., Rodriguez-Roda, I., Sieber, S., Stavenga, M., Sulis, A., Ticehurst, J., Volk, M., Wrobel, M., van Delden, H., El-Sawah, S., Rizzoli, A. \& Voinov, A., Environmental decision support systems (EDSS) development - challenges and best practices. Environmental Modelling \& Software, 26, pp. 1389-1402, 2011. doi: http://dx.doi.org/10.1016/j. envsoft.2011.09.009

[29] Ramirez, R., Stakeholder analysis and conflict management. Conflict and Collaboration in Natural Resource Management, ed. D. Buckles, Improved Data Recording Capability.and the World Bank: Ottawa and Washington, pp. 101-126, 1999. Available at http://web.idrc.ca/ev27971-201-1-DO TOPIC.html (accessed 14 October 2012).

[30] Grimble, R. \& Wellard, K., Stakeholder methodologies in natural resource management: A review of principles, contexts, experiences and opportunities. Agricultural Systems, 55, pp. 173-193, 1997.doi: http://dx.doi.org/10.1016/S0308-521X(97)00006-1

[31] Mushove, P. \& Vogel, C., Heads or tails? Stakeholder analysis as a tool for conservation area management. Global Environmental Change, 15, pp. 184-198, 2005. doi: http://dx.doi. org/10.1016/j.gloenvcha.2004.12.008

[32] Oliver, C.D. \& Twery, M.J., Decision support systems/models and analyses. Ecological Stewardship - a Common Reference for Ecosystem Management, Vol. 3, eds. W.T. Sexton, A.J. Malk, R.C. Szaro, \& N.C. Johnson, Elsevier: Oxford, pp. 661-686, 1999.

[33] Rauscher, H.M., Ecosystem management decision support for federal forests in the United States: a review. Forest Ecology and Management, 114, pp. 173-197, 1999. doi: http://dx.doi. org/10.1016/S0378-1127(98)00350-8

[34] Ellis, E.A., Bentrup, G. \& Schoeneberger, M.M., Computer-based tools for decision support in agroforestry: current state and future needs. Agroforestry Systems, 61, pp. 401-421, 2004. doi: http://dx.doi.org/10.1023/B:AGFO.0000029015.64463.65

[35] Reed, M.S., Graves, A., Dandy, N. Posthumus, H., Hubacek, K., Morris, J., Prell, C., Quinn, H. \& Stringer, L.C., Who's in and why? A typology of stakeholder analysis methods for natural resource management. Journal of Environmental Management, 90, pp. 1933-1949, 2009. doi: http://dx.doi.org/10.1016/j.jenvman.2009.01.001

[36] Rolling, N.G. \& Jiggins, J., The ecological knowledge system. Social Learning for Sustainable Agriculture, eds. N.G. Rolling \& M.A. Wagemakers, Cambridge University Press: Cambridge, pp. 283-307, 1997.

[37] Rist, S., Chidambaranathan, M., Escobar, C., Wiesmann, U. \& Zimmermann, A., Moving from sustainable management to sustainable governance of natural resources: the role of social learning processes in rural India, Bolivia and Mali. Journal of Rural Studies, 23, pp. 23-37, 2006. doi: http://dx.doi.org/10.1016/j.jrurstud.2006.02.006 
[38] Olsson, P., Folke, C. \& Hahn, T., Social-ecological transformation for ecosystem management: the development of adaptive co-management of a wetland landscape in southern Sweden. Ecology and Society, 9(4), p. 2, 2004. Available at http://www.ecologyandsociety.org/ vol9/iss4/art/2 (accessed 12 October 2012).

[39] Berkes, F., Sacred ecology: traditional ecological knowledge and management systems, Taylor and Francis: Philadelphia, Pennsylvania, USA and London, UK, 1999.

[40] Prell, C., Hubacek, K. \& Reed, M., Stakeholder analysis and social network analysis in natural resource management. Society \& Natural Resources: An International Journal, 22, pp. 501-518, 2009. doi: http://dx.doi.org/10.1080/08941920802199202

[41] ODA (Overseas Development Administration), Guidance note on how to do stakeholder analysis of aid projects and programmes, 1995. Available at http://www.sswm.info/sites/default/ files/reference_attachments/ODA\%201995\%20Guidance\%20Note\%20on\%20how\%20to\%20 do\%20a\%20Stakeholder\%20Analysis.pdf (accessed 12 October 2012).

[42] Republic of South Africa, The Communal Property Associations Act (Act No. 28 of 1996), Government Printer, Pretoria, 1996.

[43] The World Bank, Participation sourcebook. Washington, DC, USA,p. 276, 1996.

[44] Sen, S., Involving stakeholders in aquaculture policy-making, planning and management. Aquaculture in the Third Millennium, eds. R.P. Subasinghe, P. Bueno, M.J. Phillips, C. Hough, S.E. McGladdery \& J.R. Arthur, pp. 83-94. Technical Proceedings of the Conference on Aquaculture in the Third Millennium, Bangkok, Thailand, 20-25 February 2000. Bangkok, NACA, and Rome, FAO, 2001. Available at http://www.fao.org/docrep/003/AB412E/ab412e32.htm (accessed 11 October 2012).

[45] Nortje, K., Musvoto, C. \& Murambadoro, M., Elim Workshop Proceedings: improving coordination and integration of agricultural land use in restitution areas of Makhado Municipality, 2011, The Elim Workshop, Elim, Makhado Municipality, Limpopo Province, 29 August-1 September 2011. Available at http://researchspace.csir.co.za/dspace/handle/10204/5736 (accessed 8 May 2012).

[46] Kepe, T., Cousins, B. \& Turner, S., Resource tenure and power relations in community wildlife: the case of Mkambati area, South Africa. Society and Natural Resources, 14, pp. 911-925, 2001. doi: http://dx.doi.org/10.1080/089419201753242814

[47] Kull, C.A., Empowering pyromaniacs in Madagascar: ideology and legitimacy in community-based natural resource management. Development and Change, 33, pp. 57-58, 2002. doi: http://dx.doi.org/10.1111/1467-7660.00240

[48] Shackleton, S., Campbell, B., Wollenberg, E. \& Edmunds, D., Devolution and communitybased natural resource management: creating space for local people to participate and benefit? Overseas Development Institute (ODI), Natural Resource Perspectives No. 76, March 2002. Available at http://dlc.dlib.indiana.edu/dlc/bitstream/handle/10535/3646/76-devolution-community-based-natural-resource-management.pdf?sequence=1 (accessed 27 March 2012).

[49] Warner, M., Conflict management in community-based natural resource projects: experiences from Fiji and Papua New Guinea, Overseas Development Institute (ODI) Working Paper, 135, pp. 1719, 2000. Available at http://www.odi.org.uk/resources/docs/2738.pdf (accessed 11 October 2012).

[50] Chevalier, J., Stakeholder analysis and natural resource management. Carleton University: Ottawa, 2001. doi: http://httpserver.carleton.ca/ jchevali/STAKEH2.html (Accessed 10 October 2012).

[51] Billgren, C. \& Holmen, H., Approaching reality: comparing stakeholder analysis and cultural theory in the context of natural resource management. Land Use Policy, 25, pp. 550-562, 2008. doi: http://dx.doi.org/10.1016/j.landusepol.2007.11.004

[52] Davis, F.D., Perceived usefulness, perceived ease of use and user acceptance of information technology, MIS Quarterly, 13, pp. 319-340, 1989. doi: http://dx.doi.org/10.2307/249008 